\title{
Article \\ Effects of Ag Nanoparticles on Zinc Oxide Photocatalytic Performance
}

\author{
Mouna Khiari ${ }^{1,2}$, Mickaël Gilliot ${ }^{1}$, Michaël Lejeune ${ }^{2}$, Florica Lazar ${ }^{1}$ and Aomar Hadjadj ${ }^{1, *}$ \\ 1 Laboratoire d'Ingénierie \& Sciences des Matériaux, Université de Reims Champagne-Ardenne, 51687 Reims, \\ France; mouna.khiari@univ-reims.fr (M.K.); mickael.gilliot@univ-reims.fr (M.G.); \\ florica.lazar@univ-reims.fr (F.L.) \\ 2 Laboratoire de Physique de la Matière Condensée, Université de Picardie-Jules Verne, 80000 Amiens, France; \\ michael.lejeune@u-picardie.fr \\ * Correspondence: aomar.hadjadj@univ-reims.fr
}

Citation: Khiari, M.; Gilliot, M.; Lejeune, M.; Lazar, F.; Hadjadj, A. Effects of Ag Nanoparticles on Zinc Oxide Photocatalytic Performance. Coatings 2021, 11, 400. https:// doi.org/10.3390/coatings11040400

Academic Editors: Charles C. Sorrell and Joaquim Carneiro

Received: 7 February 2021

Accepted: 28 March 2021

Published: 31 March 2021

Publisher's Note: MDPI stays neutral with regard to jurisdictional claims in published maps and institutional affiliations.

Copyright: (c) 2021 by the authors. Licensee MDPI, Basel, Switzerland. This article is an open access article distributed under the terms and conditions of the Creative Commons Attribution (CC BY) license (https:// creativecommons.org/licenses/by/ $4.0 /)$.
Abstract: We used a sol-gel spin coating technique to synthesize nanocomposite thin films based on zinc oxide ( $\mathrm{ZnO}$ ) loaded with silver nanoparticles (NPs). We tested these $\mathrm{ZnO} / \mathrm{Ag}$ NPs photocatalysts, with a thickness of about $100 \mathrm{~nm}$, for the photodegradation of the indigo carmine dye solution. The study focused on the effects of Ag NPs on the $\mathrm{ZnO}$ matrix as well as the impact of their concentration on the photocatalytic performance of the nanocomposite. The study also highlighted the high stability of the photocatalytic performance of these nanocomposites. This work is a contribution in the search for non-toxic thin film photocatalysts that is usable under solar radiation for the treatment of contaminated wastewater. Innovation in the field of heterogeneous photocatalysis requires the use of solar resource with efficient results in terms of photocatalytic performance.

Keywords: ZnO; sol-gel; Ag nanoparticles; nanocomposite; photocatalysis

\section{Introduction}

Despite stringent environmental regulations, the global textile dyes market accounted for US \$ 7.59 billion in 2019 and is expected to reach US\$13.54 billion by 2027 [1]. This expected increase in the consumption of dyes will translate into an increase in water pollution since the major part of these dyes will eventually be discharged in wastewater. Currently, nearly 100 tons of dyes are released annually in effluents by industry, constantly damaging the environment and threatening human health [2]. Semiconductor photocatalysis is one of the most promising and non-expensive solution for the treatment of water contaminated by these industrial dyes. Among wide-bandgap semiconductors eligible for the process of photocatalysis and dye degradation, special attention has been given to zinc oxide $(\mathrm{ZnO})$ in recent literature due to its special features. [3-22].

As UV radiation is only a few percent of the sunlight spectrum, several approaches have been used to improve the absorption of wide-gap semiconductors in the visible, to use the sunlight as a source of irradiation. Elaboration of nanocomposites based on a wide-gap semiconductor matrix in which metallic nanoparticles (NPs) are embedded seems like a promising way to achieve this goal. Plasmonic NPs have gained a lot of attention due to their exclusive optical properties. Due to the size of the metallic NPs, possible plasmon excitations should facilitate the charge transport and separation of charge carriers [23-25] and hence improve the photocatalytic efficiency of the nanocomposite in the visible spectral range.

The beneficial contribution of Ag to the photocatalytic properties of $\mathrm{ZnO}$ has been widely reported in the literature in recent years. An important part of these studies has focused on Ag decorated $\mathrm{ZnO}$-based nanostructures due to their very advantageous surface-to-volume ratio in the photocatalysis process [26-32]. However, when the catalyst is in a nanopowder form, its separation from the treated water and its recovery for reuse 
become a major constraint. This problem does not arise in the case of $\mathrm{ZnO}$-based thin film photocatalysts, offering them a clear advantage for industrial applications.

Several manufacturing techniques exist to develop $\mathrm{ZnO}$-based thin film catalysts, such as radiofrequency sputtering [33], electrodeposition [34], spray pyrolysis [35,36], etc. Among these different techniques, sol-gel elaboration coupled with spin coating deposition offers many advantages, such as its relatively low cost and ease of elaboration, large-area deposition, good control of morphology, and the possibility to obtain a dense nanogranular $\mathrm{ZnO}$ material with improved crystallinity [37-39]. Such properties contribute to high photochemical stability. Moreover, a nanogranular $\mathrm{ZnO}$ photocatalyst presents a large specific surface area, a critical factor to influence the photocatalytic activity. In addition, improved optoelectronic properties will promote the creation of electron-hole pairs by irradiation, which in turn will generate hydroxyl radicals ${ }^{*} \mathrm{OH}$ (the neutral form of the hydroxide ion $\mathrm{OH}^{-}$) and superoxide radical anions $\mathrm{O}_{2}{ }^{-*}$. These active radicals will degrade organic pollutants until the production of $\mathrm{H}_{2} \mathrm{O}$ and $\mathrm{CO}_{2}$.

Most often, authors using the sol-gel process combine Ag precursors (silver nitrate or silver acetate) with $\mathrm{ZnO}$ precursors, [26-32,35,36]. This can lead to a substitution effect of $\mathrm{Ag}^{+}$to $\mathrm{Zn}^{2+}$ in the host lattice. To promote a plasmonic effect instead of simple electronic doping, we chose to directly include Ag NPs in the one-step $\mathrm{ZnO}$ deposition process. To our knowledge, this is the first time that such a process is reported.

The $\mathrm{ZnO}-\mathrm{Ag}$ system, as a catalyst, has been used to study the photocatalytic degradation of various dyes. Methylene blue $[26,27,30-32,36]$ and methyl orange $[26,28,34]$ are the dyes that have been studied the most. To date, no study, to our knowledge, has been devoted to the degradation of indigo carmine (IC), one of the most widely used dyes and the most polluting components found in the textile industry [40], by this type of thin film photocatalyst.

In this work, $100 \mathrm{~nm}$-thick $\mathrm{ZnO} / \mathrm{Ag}$ NPs nanocomposite thin films, elaborated by sol-gel spin coating technique, were used for the photodegradation of IC dye solution, under UV- and visible light respectively. It intends to contribute to the efforts carried out to extend the semiconductor light absorption spectrum to the visible region and to develop visible light-driven heterogeneous photocatalysts. This should favor the use of sunlight as an inexpensive and renewable energy source for photocatalytic processes.

\section{Experimental Details}

$\mathrm{ZnO} / \mathrm{Ag}$ NPs nanocomposite thin films were deposited by a one-step sol-gel spin coating technique [41]. The $\mathrm{ZnO}$ precursor solution was obtained by dissolving zinc acetate dihydrate $\left(\mathrm{Zn}\left(\mathrm{CH}_{3} \mathrm{CO}_{2}\right)_{2} \cdot 2 \mathrm{H}_{2} \mathrm{O}\right)$ in 1-propanol $\left(\mathrm{C}_{3} \mathrm{H}_{8} \mathrm{O}\right)$. Monoethanolamine $\left(\mathrm{C}_{2} \mathrm{H}_{7} \mathrm{NO}\right)$ was used as a stabilizer. We used a zinc acetate concentration of $1 \mathrm{~mol} / \mathrm{L}$, and the zinc acetate/monoethanolamine molar ratio is set to 1 . The mix was then stirred for $30 \mathrm{~min}$ at room temperature. The substrates were crystalline silicon (c-Si) coated or glass substrates. An amount of silver nanoparticles (Ag NPs), varying up to 30\%, was added to the obtained liquid and stirred in an ultrasonic bath for $5 \mathrm{~min}$ to disperse NPs in the solution. The nanocomposite was defined by the amount of Ag NPs used for its deposition. This amount represented the mass ratio between $\mathrm{Ag}$ and $\mathrm{Zn}$ in the precursor solution. After standard cleaning of the substrates with ethanol, acetone, and distilled water, the solution was aged for $24 \mathrm{~h}$ and stirred again, then deposited by spin coating at a rotation speed of $2500 \mathrm{rpm}$ for $30 \mathrm{~s}$. The $\mathrm{ZnO} / \mathrm{Ag}(\mathrm{NPs})$ nanocomposite films were subsequently pre-heated in a furnace at $300{ }^{\circ} \mathrm{C}$ for $10 \mathrm{~min}$ in order to evaporate the solvent residues. The deposition cycle, consisting of liquid deposition, spin coating, and pre-heating, leading to a film thickness of about $30 \mathrm{~nm}$, was repeated four times to obtain films with increased thickness. Finally, all samples were air-annealed at $550^{\circ} \mathrm{C}$ for $1 \mathrm{~h}$. The mentioned deposition conditions were those that led to a well-crystallized hexagonal wurtzite-type nanogranular $\mathrm{ZnO}$ matrix with a high density, a low surface roughness, and optimized optical property [37-39]. The $\mathrm{ZnO} / \mathrm{Ag}$ NPs nanocomposite thin film deposition process is schematically summarized in Figure 1. 


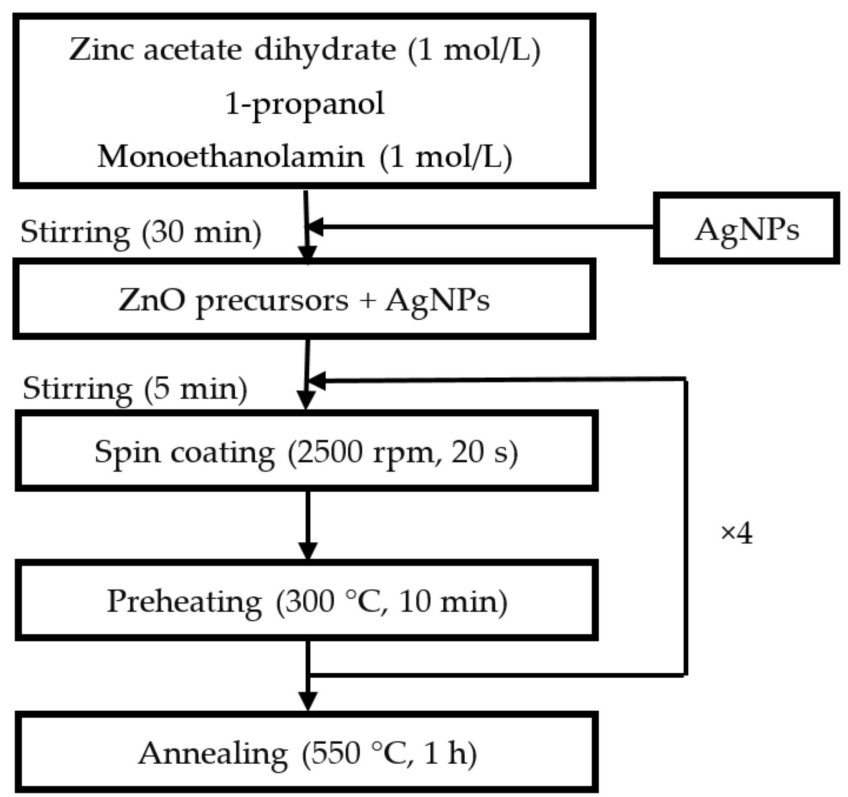

Figure 1. The $\mathrm{ZnO} / \mathrm{Ag}$ NPs nanocomposite thin films deposition process.

Ag NPs provided by US Research Nanomaterials, Inc. (Houston, TX, USA) were characterized by Transmission Electron Microscopy (TEM) (2100F, JEOL Ltd., Tokyo, Japan) and equipped with an energy dispersive X-ray (EDX) spectrometer. The morphology and chemical composition of $\mathrm{ZnO} / \mathrm{Ag}$ NPs nanocomposites were characterized by Scanning Electron Microscopy (SEM) (JSM-7900f, JEOL Ltd., Tokyo, Japan) coupled with an EDX analysis. An X-ray diffractometer (D8 Advance Bruker) equipped with a copper anticathode $(\lambda \mathrm{CuK} \alpha=1.54056 \AA)$, in the range of $30^{\circ}-80^{\circ}$, with a scan rate of $1 \mathrm{~s}$ by step, was used to analyze the structure of Ag NPs and $\mathrm{ZnO} / \mathrm{Ag}$ NPs nanocomposites.

The optical properties and the photocatalytic activity were studied with a UV-visiblenear IR spectrophotometer in the spectra range 190-800 $\mathrm{nm}$ operating in both reflective and transmission modes. The photocatalytic activity was monitored by recording the absorbance of the dye solution. As a test, we chose the most used dye in textile industries, the indigo carmine (IC: $\mathrm{C}_{16} \mathrm{H}_{8} \mathrm{~N}_{2} \mathrm{Na}_{2} \mathrm{O}_{8} \mathrm{~S}_{2}$ ), with a concentration of $6.6 \mathrm{mg} / \mathrm{L}$ in water. The illumination of the $\mathrm{ZnO} / \mathrm{Ag}$ NPs nanocomposite immersed in the solution, was provided by a $450 \mathrm{~W}\left(75 \mathrm{~mW} / \mathrm{cm}^{2}\right)$ halogen lamp, equipped with a UV cutting filter, giving an emission spectrum similar to the solar spectrum and a $1 \mathrm{~W}, 365 \mathrm{~nm}$ UV-lamp $\left(2 \mathrm{~mW} / \mathrm{cm}^{2}\right)$. For photocatalysis experiments, we used $1.5 \mathrm{~cm} \times 1.5 \mathrm{~cm}$ sized samples.

\section{Results}

\subsection{Nanoparticles Characterization}

Figure 2 shows a TEM image (a), the size distribution (b) and the XRD pattern (c) of the commercial Ag NPs used to manufacture the $\mathrm{ZnO} / \mathrm{Ag}$ NPs nanocomposite. Particle size distributions were measured with a disc centrifuge. The measurement was based on the centrifugal liquid sedimentation (CLS) method, according to Stokes law using a 405 $\mathrm{nm}$ wavelength laser [42]. Figure 2 reveals that Ag NPs are mainly $20 \mathrm{~nm}$-sized and preferentially (111) oriented. However (200), (220), and (311) Ag orientations are also present. A main size around $20 \mathrm{~nm}$ is also confirmed by the XRD diagram. TEM measurements confirm that Ag NPs present a large size distribution and tend to agglomerate. Ultrasonic agitation proves to be an effective method to break the bonds between Ag NPs and disperse them well in solution. 

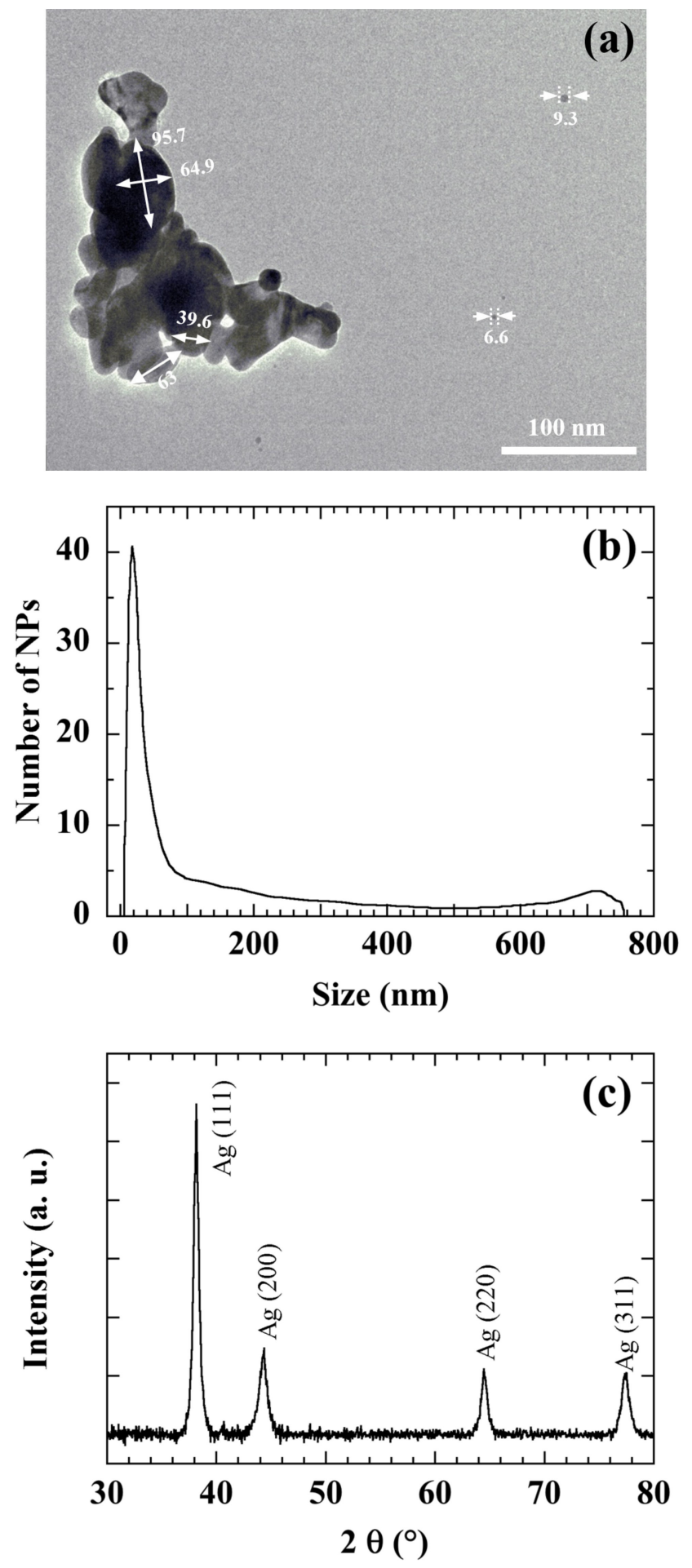

Figure 2. TEM image (a), size distribution by the CLS method (b), and X-ray diagram (c) of Ag NPs.

\subsection{Nanocomposites Characterizations}

SEM pictures of Figure 3a-c confirm the nanogranular morphology of the $\mathrm{ZnO}$ matrix previously reported [43]. These micrographs show that, starting with $20 \mathrm{~nm}$-sized Ag NPs in the deposition process, we obtain $\mathrm{ZnO}$ nanocomposite thin films containing Ag aggregates of $100 \mathrm{~nm}$ in size uniformly distributed on their surface. Their density increases with Ag NPs content. At the same time, the surface roughness increases with Ag NPs content. EDX measurements carried out on these areas confirm that they are indeed Ag aggregates (Figure 3d). We suspect the final thermal annealing at $550{ }^{\circ} \mathrm{C}$ to be responsible 
for this size variation and the cause of the diffusion of silver nanoparticles towards the surface of the film. A priori, this should favor photocatalysis reactions taking place at the surface of the photocatalyst.
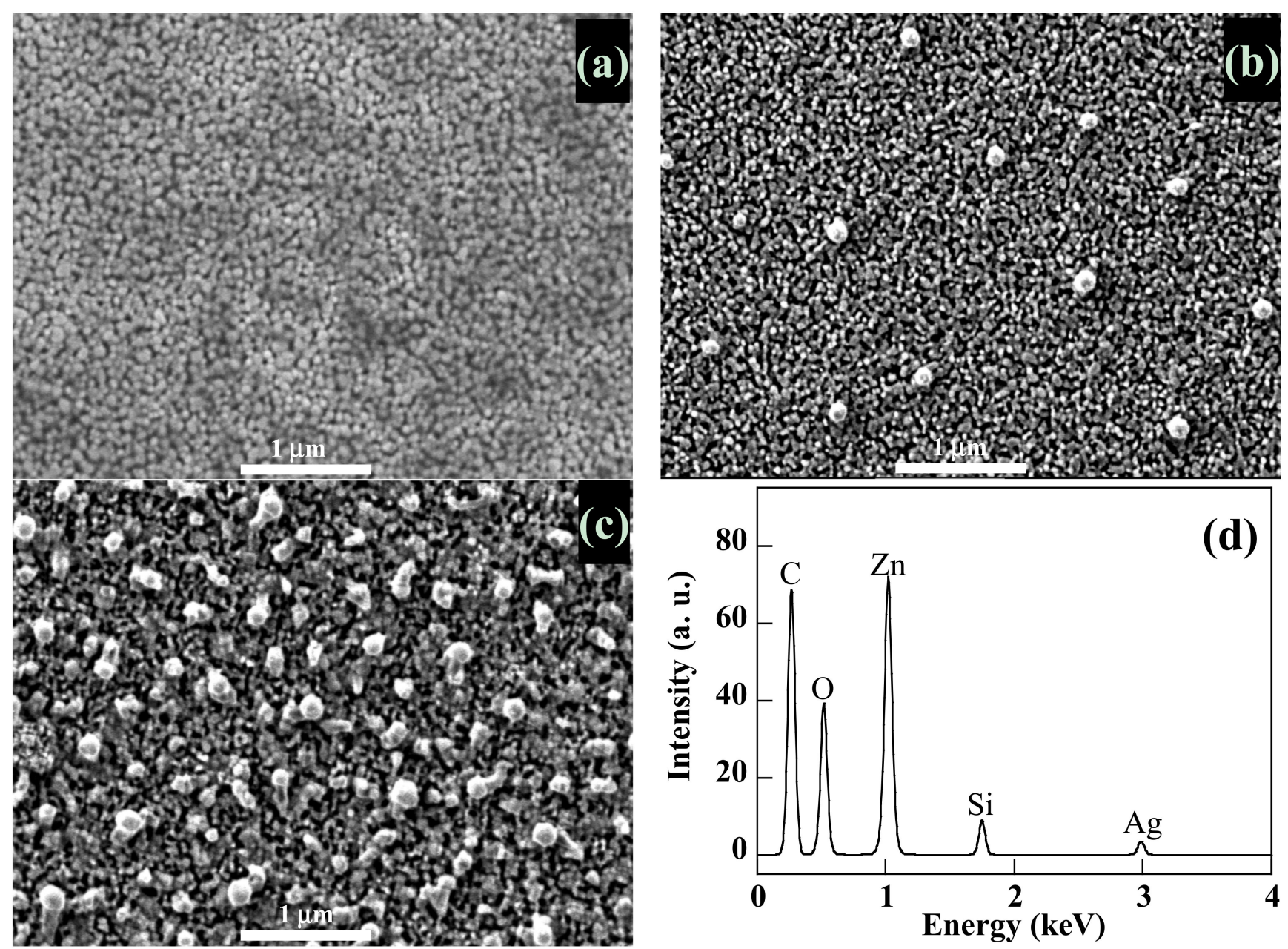

Figure 3. SEM images of pure $\mathrm{ZnO}$ thin film (a) and $\mathrm{ZnO} / \mathrm{Ag}$ NPs nanocomposite thin films with $10 \%$ (b) and $30 \%$ (c) of $\mathrm{Ag}$ NPs content and EDX spectra of an Ag NPs area (d).

The XRD diagrams of pure $\mathrm{ZnO}$ and $\mathrm{ZnO} / \mathrm{Ag}$ NPs nanocomposite thin films deposited on the c-Si substrate are reported in Figure 4 . The spectra present only significant contribution in the $30^{\circ}$ to $40^{\circ}$ of $2 \theta$ range, showing peaks pointing around $32.0^{\circ}, 34.6^{\circ}$, and $36.4^{\circ}$ respectively attributed, according to JCPDS 36-1451 of bulk $\mathrm{ZnO}$ [44] to (100), (002) and (101) orientations. The spectra present the dominant (002) peak revealing a perfect crystallinity with the Wurtzite phase of $\mathrm{ZnO}$ with a c-axis perpendicular to the substrate plane. The $\mathrm{ZnO} / \mathrm{Ag}$ NPs nanocomposite is characterised by the presence of (111) and (200) $\mathrm{Ag}$ peaks located at $38.1^{\circ}$ and $44.2^{\circ}$ respectively and whose intensity increases with Ag NPs content. The (002) mean $\mathrm{ZnO}$ peak slightly decreases until reaching $10 \%$ of $\mathrm{Ag}$ NPs. The decrease is more significant beyond $10 \%$ of Ag NPs, and goes with a relative enhancement of the (101) peak. 


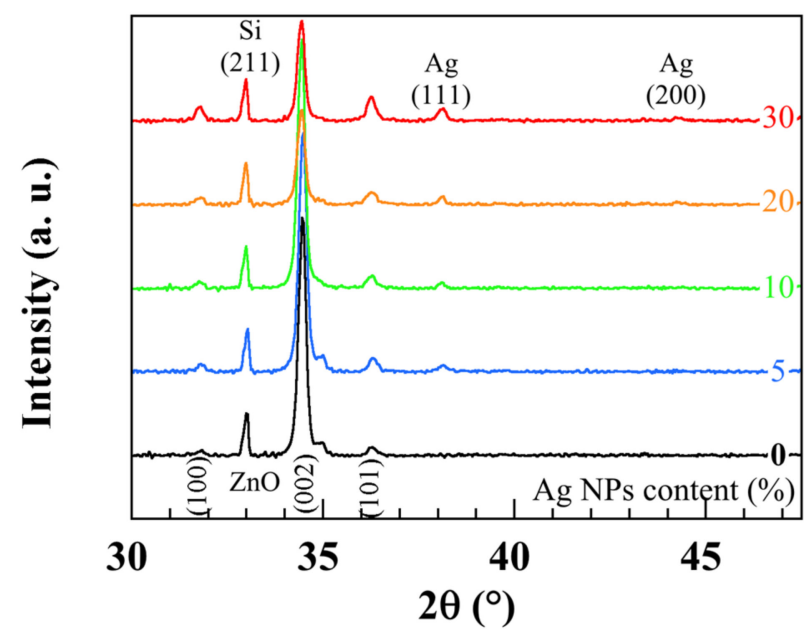

Figure 4. XRD diagram of pure $\mathrm{ZnO}$ and $\mathrm{ZnO} / \mathrm{Ag}$ NPs nanocomposites.

The optical properties were investigated using UV-visible-near IR reflective and transmission measurements within a $270-800 \mathrm{~nm}$ spectral range, on nanocomposite thin films deposited on glass substrates. Figure 5 shows the absorption spectra of $\mathrm{ZnO} / \mathrm{Ag}$ NPs nanocomposites with various Ag NPs contents. The absorption spectrum of $\mathrm{ZnO}$ is significantly modified by the embedded Ag NPs:

(i) Since with the smallest Ag NPs content, a red-shift of the absorption onset arises indicating a bandgap narrowing.

(ii) The excitonic peak of $\mathrm{ZnO}$ shifts to a lower energy and with a lower amplitude.

(iii) An additional absorption, due to Ag NPs, arises in the spectral zone lower than $3 \mathrm{eV}$. This additional sub-gap absorption due to Ag NPs [45] increases with their content.

(iv) The absorption in the UV part of the spectrum decreases however.

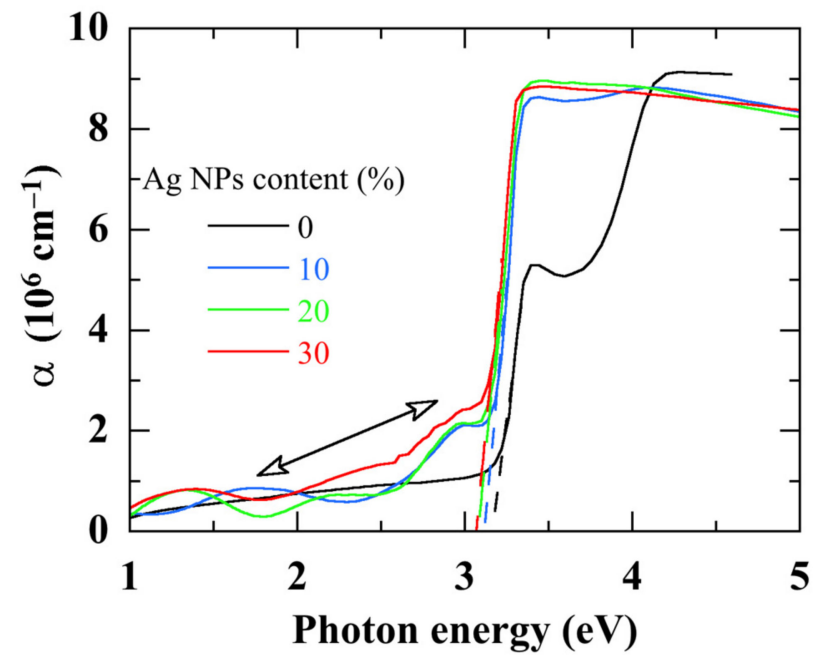

Figure 5. Absorption coefficient $\alpha$ of pure $\mathrm{ZnO}$ thin film and $\mathrm{ZnO} / \mathrm{Ag}$ NPs nanocomposite thin films. The dashed lines indicate the absorption edges and the arrow indicates the additional absorption due to Ag NPs.

\subsection{Photocatalytic Activity}

Before carrying out the photodegradation experiments, we first verified that, in the framework of our experimental protocol (see Figure 6), the degradation of the IC dye solution is only due to our photocatalyst. For this purpose, different experiments were conducted: 
- Once the solution was prepared, we measured its absorbance without any contact with the catalyst (Figure 7a). The absorption peaks at 280 and $610 \mathrm{~nm}$ are characteristic of IC [46]. They are attributed to the indigoid group present as chromophore center in IC [47]. Then, we let it stand for one hour in the dark. The absorbance spectrum after one hour in the dark indicated perfect stability of the IC dye solution (Figure 7a).

- We then exposed the solution to white light for one hour. Figure $7 \mathrm{~b}$ shows that the absorbance spectrum remains unchanged, especially in the absorption region of IC, indicating that the illumination did not cause any degradation of the dye solution.

- To clarify the exact role of silver in the photodegradation process, we used a $50 \mathrm{~nm}$ thick Ag thin film sputtered onto a crystalline silicon substrate as a catalyst. After one hour of white light illumination, the absorbance spectrum of the solution did not change (Figure 7c). In conclusion, Ag film alone had no photocatalytic activity.

- We also checked the role of a possible thermal effect, during the photodegradation of IC dye solution, due to the IR part of the white light. For this, we heated the solution at $60^{\circ} \mathrm{C}$ for one hour in the dark and in the presence of the $\mathrm{ZnO} / \mathrm{Ag}$ catalyst. The absorbance spectrum of the IC dye solution remained unchanged (Figure 7d).

After discarding all these parameters, we are confident that the effects observed during the photocatalysis experiments can be attributed only to the $\mathrm{ZnO} / \mathrm{Ag}$ catalysts.

Figure 8 displays the absorbance spectra of the IC solution recorded during different times of photocatalytic activity of a nanocomposite with $10 \%$ of Ag NPs, under visible (a) and UV (b) light illumination. We note a regular decrease of both peaks during the illumination time. After nearly $6 \mathrm{~h}$ of degradation, the peak at $610 \mathrm{~nm}$ loses almost $85 \%$ of its initial amplitude with a UV light against $27 \%$ with a visible light. At the same time, the accumulation in the aqueous dye solution of species resulting from the IC degradation leads to some increase in the $250 \mathrm{~nm}$ peak intensity [46].

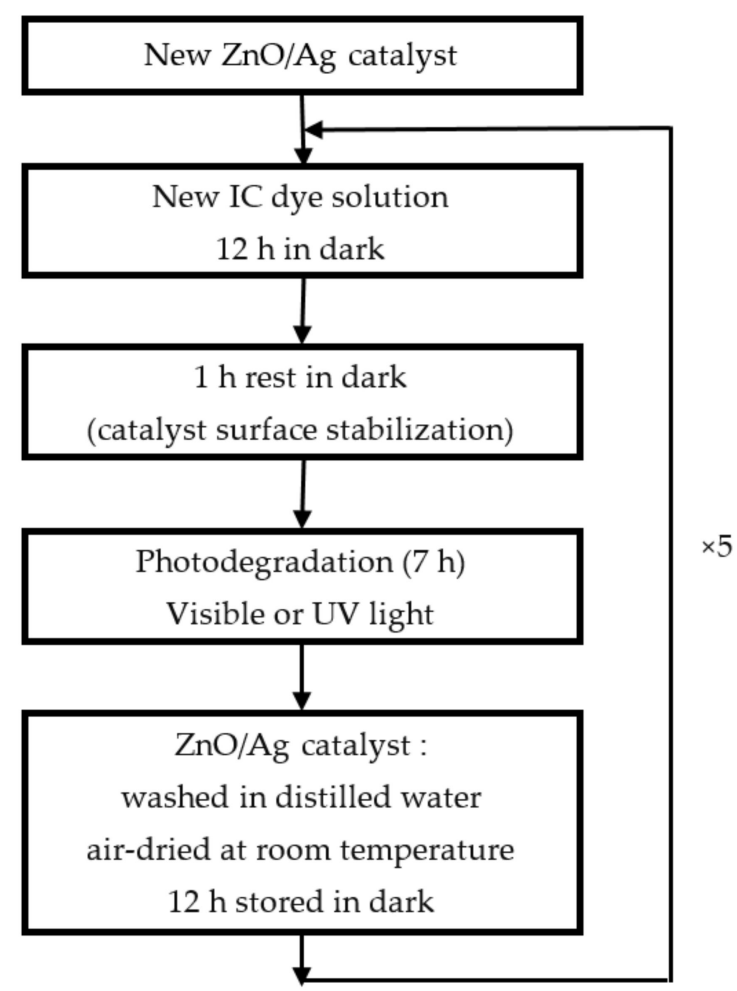

Figure 6. The protocol for studying the reuse of $\mathrm{ZnO} / \mathrm{Ag}$ NPs nanocomposite. 

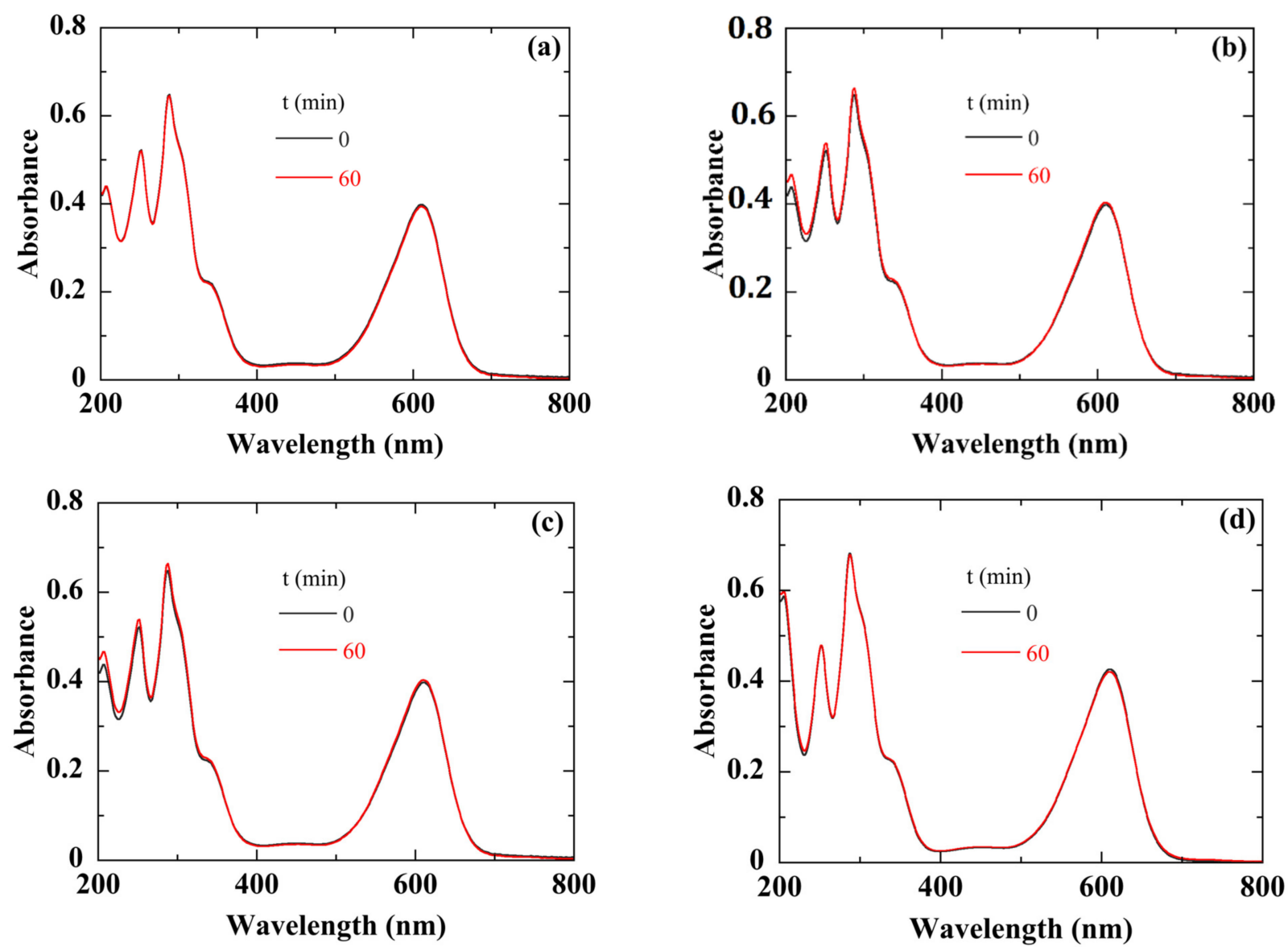

Figure 7. Absorbance of the IC solution after one hour: (a) in dark and without catalyst, (b) under white light illumination and without catalyst, (c) under white light illumination in the presence of Ag thin film, (d) in dark under thermal annealing at $60^{\circ}$ in the presence of a catalyst.
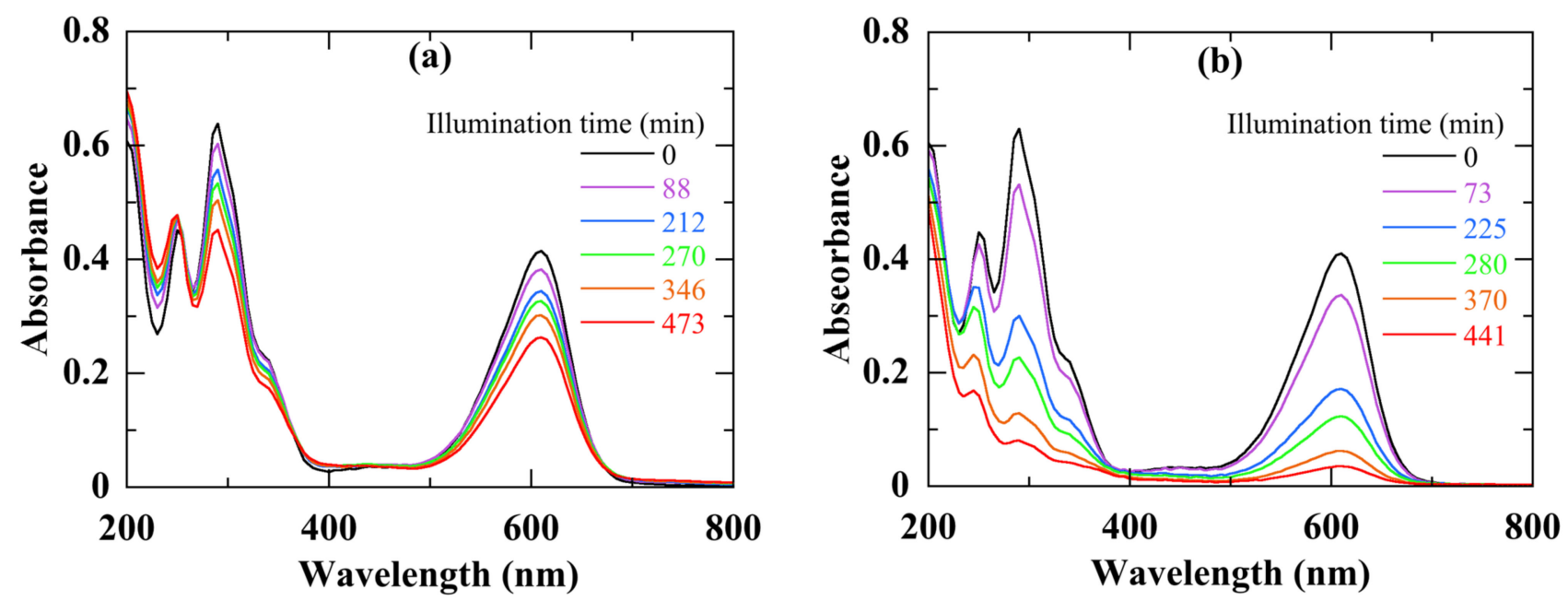

Figure 8. Absorbance of the IC solution after different times of degradation, under visible- (a) and UV- (b) light illumination. The used catalyst was a nanocomposite with $10 \%$ of Ag NPs.

As the dye absorbance band at $610 \mathrm{~nm}$ is proportional to its concentration $C$, the discoloration rate (or degradation efficiency) $\eta$ after an illumination duration $t$, can be defined by:

$$
\eta(\%)=100\left(1-\frac{C}{C_{0}}\right)
$$


where $C_{0}$ is the initial IC concentration before illumination, and $C$ its value after a photodegradation duration $t$. Results obtained with both visible-light (a) and UV-light (b) are reported in Figure 9. First, whatever the illumination source, the $\mathrm{ZnO} / \mathrm{Ag}$ NPs nanocomposite thin film shows a higher photocatalytic activity in comparison with pure $\mathrm{ZnO}$ thin film. This difference increases over time. For the same sample, the value of $\eta$ more than doubles when white light is used. The discoloration with $\mathrm{ZnO} / \mathrm{Ag}$ NPs nanocomposite shows a linear trend and its photocatalytic activity seems to be able to continue with the same trend well beyond the time limit of the experiment $(>6 \mathrm{~h})$. Undoubtedly, the presence of Ag NPs improves the photocatalytic performance of $\mathrm{ZnO}$ thin films.
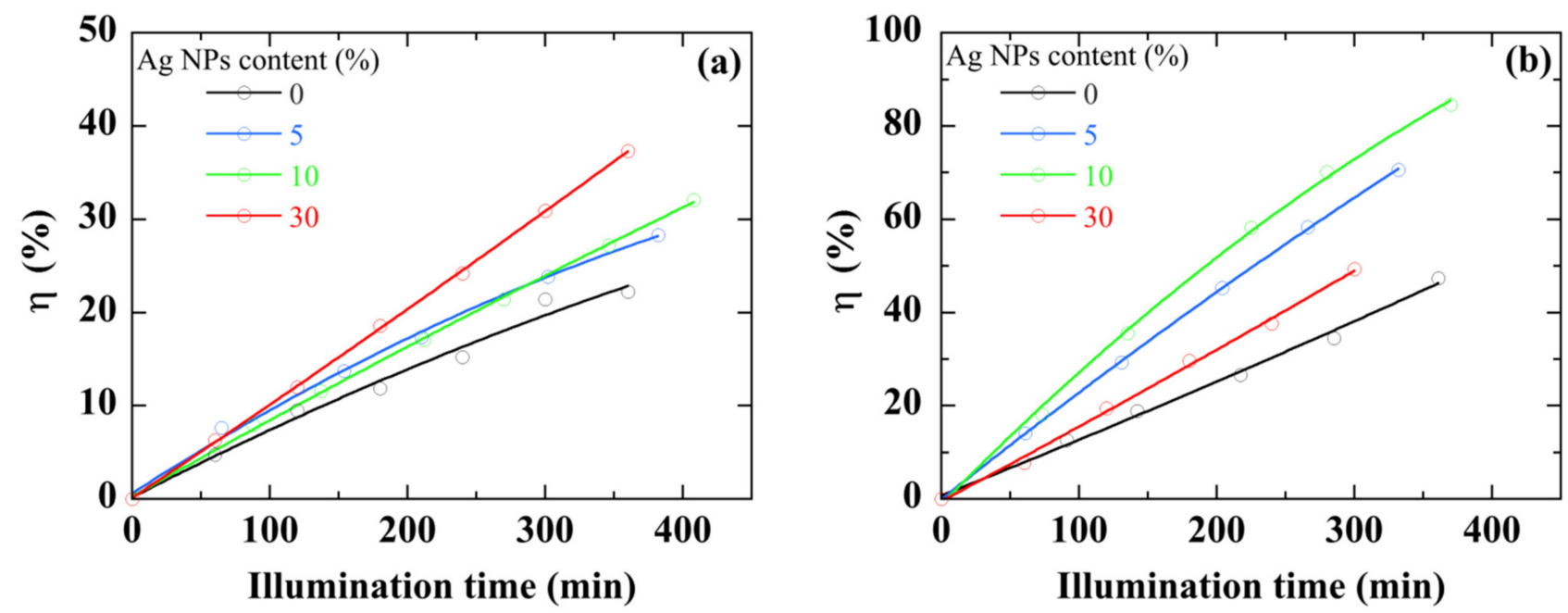

Figure 9. IC degradation percentage with $\mathrm{ZnO}$ and $\mathrm{ZnO} / \mathrm{Ag}$ NPs nanocomposite thin films under visible- (a) and UV(b) light illumination. The curves are provided as guides for the eye.

In the case of low concentrations of dyes, the pseudo-first-order kinetic model is generally used to quantitatively analyze its kinetics degradation. A pseudo-first-order rate constant $k$ characterizes changes in concentration over time:

$$
\ln \left(\frac{C}{C_{0}}\right)=-k t
$$

This apparent first-order rate constant $k$ is a useful tool to evaluate the photocatalytic performance of a sample. Figure 10 shows the rate constant of nanocomposites with different Ag NPs content and illuminated with either visible light or UV light. Unsurprisingly, the photocatalytic activity with UV illumination is two to five times greater than with visible light. When Ag NPs content increases up to $10 \%, k$ increases from $16 \times 10^{-4}$ to $45 \times 10^{-4} \mathrm{~min}^{-1}$ with a UV light. Further increase in Ag NPs content drops the rate constant to $20 \times 10^{-4} \mathrm{~min}^{-1}$ at the highest Ag NPs content. Using a white light leads to a very low IC degradation rate constant which monotonously and linearly increases from $7 \times 10^{-4}$ to $12 \times 10^{-4} \mathrm{~min}^{-1}$ with Ag NPs content. The existence of an optimal metallic NPs concentration for improving the catalytic activity of a semiconductor under UV illumination has already been demonstrated [48-50]. 


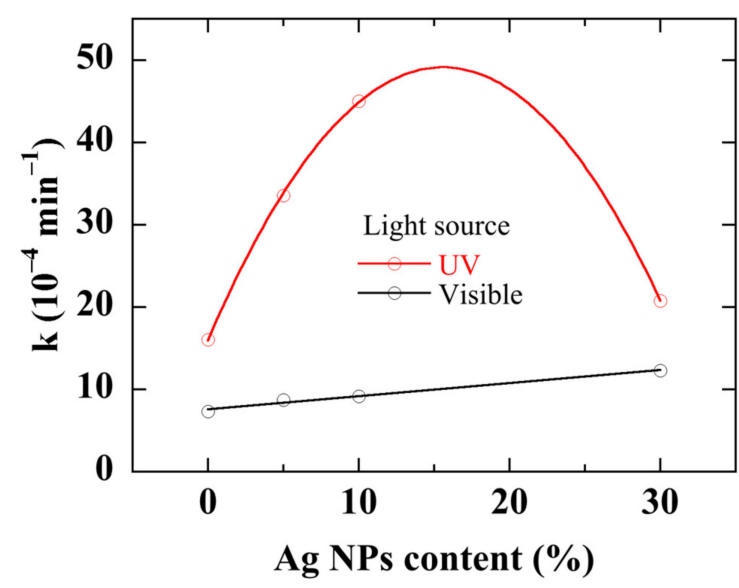

Figure 10. Degradation rate constant with $\mathrm{ZnO} / \mathrm{Ag}$ NPs nanocomposites with various Ag NPs content under UV- and visible light illumination. The curves are provided as guides for the eye.

Reusability is a key feature sought after for photocatalysts in technological applications. The protocol for studying the reuse is schematically summarized in Figure 6. The tests reported in Figure 11, in terms of degradation efficiency (a) and rate constant (b) after $7 \mathrm{~h}$, were performed on a new sample with the most effective Ag NPs content of 10\%. The sample was used during five runs of $7 \mathrm{~h}$ of photo catalysis. After each photocatalytic experiment, the dye solution was renewed, and the catalyst was washed by distilled water, dried in air at room temperature, and kept in the dark for $12 \mathrm{~h}$. Figure 11 infers the following conclusions:

(i) The $\mathrm{ZnO} / \mathrm{Ag}$ NPs catalyst can maintain a stable and efficient photocatalytic performance over five photocatalytic cycles.

(ii) The first cycle seems to be a step of activating the sample surface, more particularly under visible light illumination, since its photocatalytic performance improves thereafter.

(iii) Up to five cycles, a marginal decrease in photocatalytic efficiency of $5 \%$ is observed. Under UV illumination, the rate constant drops by $12 \%$. This may be due to a decrease of active sites on the catalytic surface [51]. Oxidation/corrosion and/or dissolution of the noble metal particles during the photocatalytic operation are also usually evoked as a problem for long-term use and stability [52].

(iv) After $7 \mathrm{~h}$ of use, no visible deterioration on the surface of the catalyst can be reported. The thin film of nanocomposite can be used for a longer period.
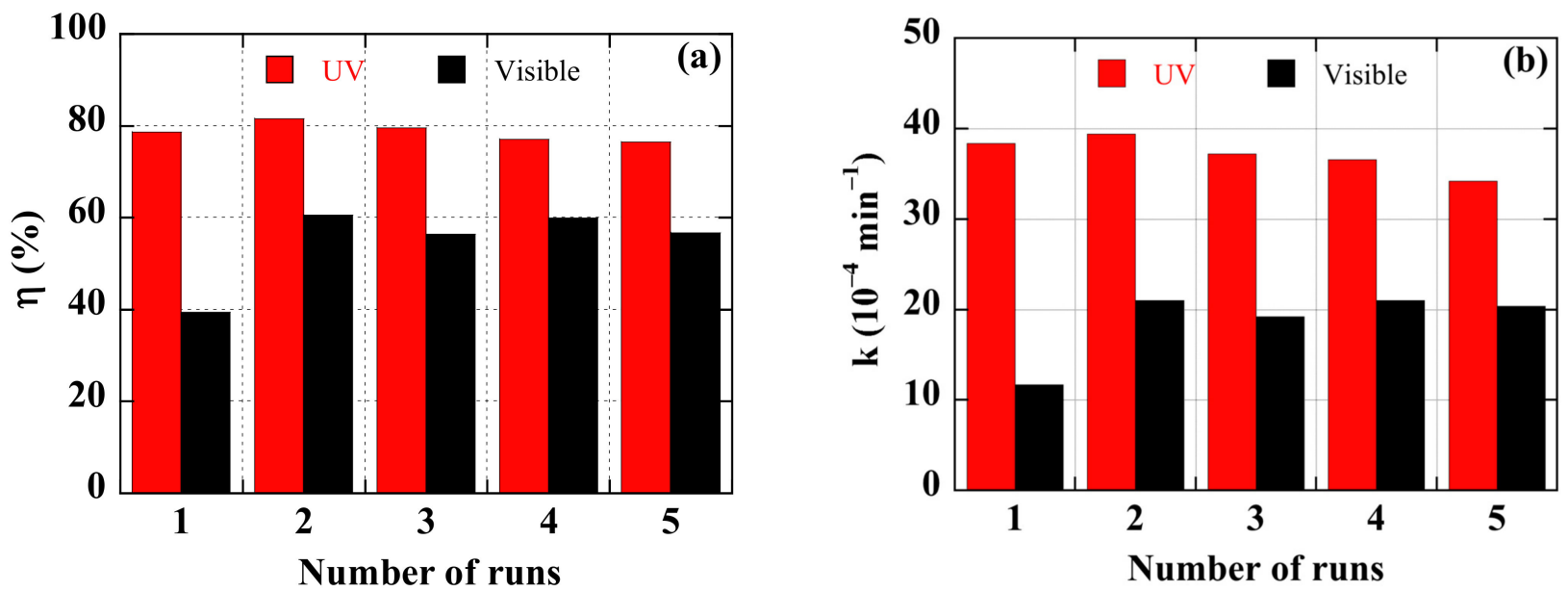

Figure 11. Reusability of a $\mathrm{ZnO} / \mathrm{Ag}$ NPs nanocomposite thin film, with $10 \%$ of Ag NPs, for degradation of the IC solution, under visible- and UV-light illumination. (a) Degradation efficiency after $7 \mathrm{~h}$, (b) rate constant. 


\section{Discussion}

Heterogeneous photocatalysis using a photocatalyst, with a bandgap of energy $E_{\mathrm{g}}$, leads to the total mineralization of the dye molecule thanks to the possible following mechanism [48,53]:

(i) When the photocatalyst is illuminated by a photon of energy $h v \geq E_{\mathrm{g}}$ (UV light illumination), its absorption generates an electron $\left(\mathrm{e}^{-}\right)$-hole $\left(\mathrm{h}^{+}\right)$pair in, respectively, the conduction band (CB) and the valence band (VB) of the semiconductor (Figure 12a):

$$
(\mathrm{ZnO})+h v \rightarrow e^{-}+h^{+}
$$

(ii) The photo-generated electron-hole pairs lead to oxidation-reduction reactions with dioxygen $\left(\mathrm{O}_{2}\right)$ and aqueous $\left(\mathrm{H}_{2} \mathrm{O}\right)$ in the dye solution to form free radicals like ${ }^{*} \mathrm{O}_{2}{ }^{-}$ and ${ }^{*} \mathrm{OH}$ :

$$
\begin{gathered}
\left(\mathrm{O}_{2}\right)_{\mathrm{ads}}+e^{-} \rightarrow{ }^{*} \mathrm{O}_{2}^{-} \\
\left(\mathrm{H}_{2} \mathrm{O} \Leftrightarrow \mathrm{H}^{+}+\mathrm{OH}^{-}\right)_{\text {ads }}+h^{+} \rightarrow \mathrm{H}^{+}+{ }^{*} \mathrm{OH}
\end{gathered}
$$

(iii) The degradation of the dye molecule occurs via successive attacks by active radicals until the production of $\mathrm{H}_{2} \mathrm{O}$ and $\mathrm{CO}_{2}$.

The presence of Ag NPs in the $\mathrm{ZnO}$ thin film produces a Schottky barrier (Figure 12a). Consequently, Ag NPs behave like electron sinks which provide sites for attracting the photogenerated electrons and accelerating electron-hole pairs separation [48]:

$$
\mathrm{Ag}^{+}+e^{-} \rightarrow \mathrm{Ag}
$$

Ag NPs enhance the photocatalytic activity by increasing the lifetime of the photogenerated electron-hole pairs. However, beyond an optimal Ag NPs concentration, the over-accumulation of electron on Ag NPs could attract the photo-generated holes, and this may encourage the recombination of charge carriers [24,48]. As a consequence, the photocatalytic performance drops (Figure 9).

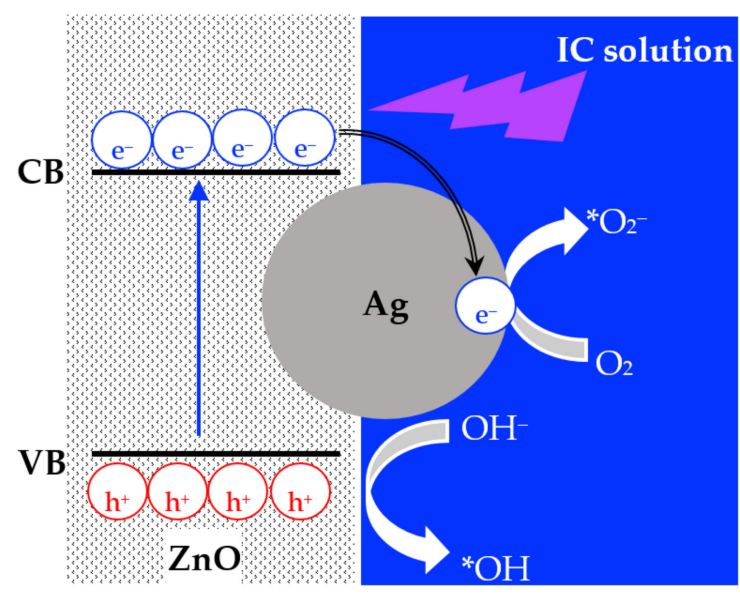

(a)

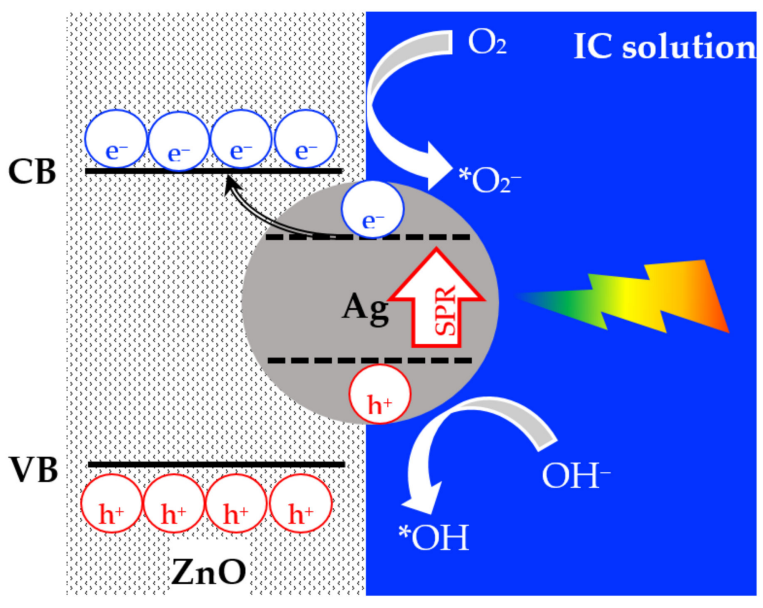

(b)

Figure 12. Scheme of plausible electron transfer into ZnO/Ag NPs composite upon UV (a) and visible (b) light illumination. In the latter case, electron transfer could be mediated by possible surface plasmon resonance (SPR) of Ag NPs.

Furthermore, the photocatalytic reaction rate strongly depends on other properties such as the particle size, the surface area and the crystalline form [52]. The significant decrease of the dominant (002) peak of $\mathrm{ZnO}$ (Figure 4) beyond 10\% of Ag NPs can be linked to the drop of the rate constant of Figure 10. As previously mentioned, the specific surface area is a key factor in photocatalytic activity. A high Ag NPs content (Figure 3c) 
may reduce the availability of semiconductor surfaces for light absorption and pollutant adsorption and then decrease the catalytic efficiency of the catalyst.

Moreover, when Ag NPs are embedded in the ZnO matrix, defect-associated gap states lead to a sub-bandgap absorption and a bandgap narrowing of the material (Figure 5). Both effects contribute to the improvement of the absorption in the visible range and then the photocatalytic activity under visible light illumination (Figure 10).

Other effects linked to the particular properties of Ag NPs can have a beneficial impact on the photocatalytic activity of the nanocomposite [54,55]:

(i) Surface plasmon resonance of Ag NPs could create an enhanced local electric field on the surface of $\mathrm{ZnO}$, which improves the activity of the catalyst under visible light irradiation.

(ii) Electron transfer from excited $\mathrm{Ag} \mathrm{NPs}$ to $\mathrm{ZnO}$, mediated by $\mathrm{Ag}$ surface plasmons under visible light irradiation (Figure 12b), could activate oxygen at the oxide surface (Equation (4)).

(iii) Indirect transfer of photons from $\mathrm{Ag} \mathrm{NPs}$ to $\mathrm{ZnO}$ via radiative decay of surface plasmon states could excite electrons in $\mathrm{ZnO}$ and increase electron-hole pair generation.

These different effects, enhanced with Ag NPs content, may explain the continuous improvement in the photocatalytic performance observed under white light illumination (Figure 10). However, these effects related to surface plasmon resonance depend on several physicochemical parameters such as the particle size, the shape, and the inter-nanoparticle gap [56-59].

The photocatalytic efficiency depends on the type of catalyst, the nature of the dye, and the experimental conditions (light power, the surface of the catalyst, the concentration of the solution, its $\mathrm{pH}$, etc.). Additionally, the comparison of the obtained results with those of the literature is not easy. However, as the stability and efficiency is a critical factor for the industrial application of a catalyst, we will mention some of the studies done on the degradation of indigo carmine with $\mathrm{ZnO}$-based catalysts and focus on the stability and efficiency of their photocatalytic performance during the degradation cycles. Shinde et al. [51] used Ni, C, N, S and multi-doped $\mathrm{ZnO}$ nanospheres for the degradation of IC at higher $\mathrm{pH}$ under solar light exposure. These authors concluded that the reusability of their catalyst is not efficient beyond the third cycle. Labhane et al. [60] synthesized and studied the photocatalytic activities of $\mathrm{Mg}$-doped $\mathrm{ZnO}$ nanoparticles decorated on graphene oxide (GO). They reached nearly $99 \%$ of IC degradation within 60 min under sunlight. Their photocatalytic efficiency decreased by about $5-6 \%$ after four cycles. Prado et al. [61] compared the photocatalytic ability of $\mathrm{Nb}_{2} \mathrm{O}_{5}, \mathrm{TiO}_{2}$, and $\mathrm{ZnO}$ powders in degradation of IC under a $125 \mathrm{~W}$ mercury-vapour lamp illumination. They showed that the activity of $\mathrm{ZnO}$ catalysts decreased drastically to $20 \%$ of dye degradation, respectively, after 10 reaction cycles. Güy and Özacar [62] used Tannin $/ \mathrm{ZnFe}_{2} \mathrm{O}_{4} / \mathrm{ZnO}$ powder for the degradation of IC in an aqueous solution under UV and visible light. They found degradation ratios of $82 \%$ and $99 \%$ after illumination for 90 min under UV light and visible light, respectively. After five times recycling, under visible the photocatalytic IC degradation performance of their catalyst decreased up to $90 \%$ after five cycles under visible light.

Finally, it should be noted that in the studies mentioned above, the authors used a catalyst in powder form, for which the recovery before reuse is a real drawback.

\section{Conclusions}

$\mathrm{ZnO} / \mathrm{Ag}$ NPs nanocomposites thin films have been successfully produced by solgel spin coating technique, with Ag NPs content varying up to $30 \%$. While the initial average size of the nanoparticles was $20 \mathrm{~nm}$, their average size, once embedded in the nanocomposite, became of the order of $100 \mathrm{~nm}$. The photocatalytic performance of $\mathrm{ZnO} / \mathrm{Ag}$ NPs nanocomposites in the degradation of IC has been probed using either UV or visible light illumination. Under UV-light illumination, the photocatalytic performance is greatly enhanced until an optimal Ag NPs content ranging between $10 \%$ and $20 \%$. Under visible light illumination, the moderate improvement increases steadily with the Ag NPs content. 
The photocatalytic performance of the nanocomposites has shown remarkable stability during 5 runs of $7 \mathrm{~h}$ of IC degradation.

Direct sol-gel spin-coating deposition of $100 \mathrm{~nm}$-thick $\mathrm{ZnO} / \mathrm{Ag}$ NPs, with metallic NPs at the surface of the photocatalyst and in direct contact with the pollutant, is the chief strength of the study. Further investigations are needed to better tune the plasmonic properties of nanoparticles, in particular, by reducing the size of Ag NPs, for better sunlight application. Another track that we plan to explore is the use of NPs of a less expensive metal, such as copper or copper oxide, for example.

Author Contributions: Conceptualization and methodology, M.G., M.L., and A.H.; validation, M.L., M.G., and A.H.; investigation, M.K. and F.L.; writing—original draft preparation, M.K.; writingreview and editing, A.H.; funding acquisition, A.H. and M.L. All authors have read and agreed to the published version of the manuscript.

Funding: This research received no external funding.

Institutional Review Board Statement: Not applicable.

Informed Consent Statement: Not applicable.

Data Availability Statement: The data presented in this study are available on request from the corresponding author.

Acknowledgments: This work was supported by Grand-Est Region and Hauts-de-France Region under the PHOTOSOL Grant, within a fruitful collaboration between LISM and LPMC laboratories.

Conflicts of Interest: The authors declare no conflict of interest.

\section{References}

1. Global Textile Dyes Market Research Report 2018-2020, 2024 \& 2027, August 04, 2020 04:58 ET. Available online: https: / / www.globenewswire.com/news-release/2020/08/04/2072195/0/en/Global-Textile-Dyes-Market-Research-Report2018-2020-2024-2027.html (accessed on 31 January 2021).

2. Fan, J.; Chen, D.; Li, N.; Xu, Q.; Li, H.; He, J.; Lu, J. Adsorption and biodegradation of dye in wastewater with $\mathrm{Fe}_{3} \mathrm{O}_{4} @ \mathrm{MIL}^{-100}$ (Fe) core-shell bio-nanocomposites. Chemosphere 2018, 191, 315-323. [CrossRef]

3. Weldegebrieal, G.K. Synthesis method, antibacterial and photocatalytic activity of ZnO nanoparticles for azo dyes in wastewater treatment: A review. Inorg. Chem. Commun. 2020, 120, 108140. [CrossRef]

4. Sun, Y.; Liu, Y.; Xu, F.; Sun, L. Preparation of metal spinel oxides for photocatalytic degradation of organic pollutants: A review. Cailiao Daobao Mater. Rep. 2020, 34, 15021-15032.

5. Karthikeyan, C.; Arunachalam, P.; Ramachandran, K.; Al-Mayouf, A.M.; Karuppuchamy, S. Recent advances in semiconduc-tor metal oxides with enhanced methods for solar photocatalytic applications. J. Alloys Compd. 2020, 828, 154281. [CrossRef]

6. Yu, F.; Nan, D.; Wang, B.; Liu, Z.; Li, Y.; He, L.; Tang, X.; Zhang, J. Catalytic properties of the composite of La-doped ZnO nano-rods and $\mathrm{Ag}_{2} \mathrm{CrO}_{4}$ nanoparticles. Appl. Phys. A Mater. Sci. Process. 2020, 126, 482. [CrossRef]

7. Mimouni, R.; Askri, B.; Larbi, T.; Amlouk, M.; Meftah, A. Photocatalytic degradation and photo-generated hydrophilicity of Meth-ylene Blue over $\mathrm{ZnO} / \mathrm{ZnCr}_{2} \mathrm{O}_{4}$ nanocomposite under stimulated UV light irradiation. Inorg. Chem. Commun. 2020, 115, 107889. [CrossRef]

8. Hussain, S.M.; Hussain, T.; Faryad, M.; Ali, Q.; Ali, S.; Rizwan, M.; Hussain, A.I.; Ray, M.B.; Chatha, S.A. Emerging aspects of photo-catalysts $\left(\mathrm{TiO}_{2} \& \mathrm{ZnO}\right)$ doped zeolites and advanced oxidation processes for degradation of azo dyes: A review. Curr. Anal. Chem. 2020, 17, 82-97. [CrossRef]

9. Sharma, R.; Garg, R.; Kumari, A. A review on biogenic synthesis, applications and toxicity aspects of zinc oxide nanoparticles. EXCLI J. 2020, 19, 1325-1340.

10. Anwer, H.; Mahmood, A.; Lee, J.; Kim, K.-H.; Park, J.-W.; Yip, A.C.K. Photocatalysts for degradation of dyes in industrial efflu-ents: Opportunities and challenges. Nano Res. 2019, 12, 955-972. [CrossRef]

11. Samadi, M.; Zirak, M.; Naseri, A.; Kheirabadi, M.; Ebrahimi, M.; Moshfegh, A.Z. Design and tailoring of one-dimensional ZnO nanomaterials for photocatalytic degradation of organic dyes: A review. Res. Chem. Intermed. 2019, 45, 2197-2254. [CrossRef]

12. Ashouri, R.; Ghasemipoor, P.; Rasekh, B.; Yazdian, F.; Mofradnia, S.R.; Fattahi, M. The effect of ZnO-based carbonaceous mate-rials for degradation of benzoic pollutants: A review. Int. J. Environ. Sci. Technol. 2019, 16, 1729-1740. [CrossRef]

13. Din, M.I.; Najeeb, J.; Ahmad, G. Recent advancements in the architecting schemes of zinc oxide-based photocatalytic assemblies. Sep. Purif. Rev. 2017, 47, 267-287. [CrossRef]

14. Laurenti, M.; Cauda, V. Porous zinc oxide thin films: Synthesis approaches and applications. Coatings 2018, 8, 67. [CrossRef] 
15. Liu, X.; Iocozzia, J.; Wang, Y.; Cui, X.; Chen, Y.; Zhao, S.; Li, Z.; Lin, Z. Noble metal-metal oxide nanohybrids with tailored nanostructures for efficient solar energy conversion, photocatalysis and environmental remediation. Energy Environ. Sci. 2017, 10, 402-434. [CrossRef]

16. Han, S.W.; Kim, K.-D.; Kim, J.H.; Uhm, S.; Kim, Y.D. Hydrophobic polydimethylsiloxane thin films prepared by chemical vapor deposition: Application in water purification. Appl. Chem. Eng. 2017, 28, 1-7.

17. Ray, C.; Pal, T. Recent advances of metal-metal oxide nanocomposites and their tailored nanostructures in numerous catalytic applica-tions. J. Mater. Chem. A 2017, 5, 9465-9487. [CrossRef]

18. Gandha, K.; Mohapatra, J.; Hossain, M.K.; Elkins, K.; Poudyal, N.; Rajeshwar, K.; Liu, J.P. Mesoporous iron oxide nanowires: Synthesis, magnetic and photocatalytic properties. RSC Adv. 2016, 6, 90537-90546. [CrossRef]

19. Julkapli, N.M.; Bagheri, S.; Hamid, S.B.A. Recent advances in heterogeneous photocatalytic decolorization of synthetic dyes. Sci. World J. 2014, 2014, 1-25. [CrossRef]

20. Yin, B.; Zhang, S.; Zhang, D.; Jiao, Y.; Liu, Y.; Qu, F.; Wu, X. ZnO film photocatalysts. J. Nanomater. 2014, 2014, 1-7. [CrossRef]

21. Udom, I.; Ram, M.K.; Stefanakos, E.K.; Hepp, A.F.; Goswami, D.Y. One dimensional-ZnO nanostructures: Synthesis, properties and environmental applications. Mater. Sci. Semicond. Process. 2013, 16, 2070-2083. [CrossRef]

22. Lam, S.-M.; Sin, J.-C.; Abdullah, A.Z.; Mohamed, A.R. Degradation of wastewaters containing organic dyes photocatalysed by zinc oxide: A review. Desalin. Water Treat. 2012, 41, 131-169. [CrossRef]

23. Sanzone, G.; Zimbone, M.; Cacciato, G.; Ruffino, F.; Carles, R.; Privitera, V.; Grimaldi, M. Ag/TiO 2 nanocomposite for visible light-driven photocatalysis. Superlattices Microstruct. 2018, 123, 394-402. [CrossRef]

24. Madhavi, V.; Kondaiah, P.; Raman, K.T.; Shaik, H.; Rao, G.M. Corrigendum to "Influence of silver nanoparticles on titanium oxide and nitrogen doped titanium oxide thin films for sun light photocatalysis". Appl. Surf. Sci. 2018, 440, 1299. [CrossRef]

25. Shan, Z.; Wu, J.; Xu, F.; Huang, F.-Q.; Ding, H. Highly effective silver/semiconductor photocatalytic composites prepared by a silver mirror reaction. J. Phys. Chem. C 2008, 112, 15423-15428. [CrossRef]

26. Stanley, R.; Alphas Jebasingh, J.; Manisha Vidyavathy, S.; Kingston Stanley, P.; Ponmani, P.; Shekinah, M.E.; Vasanthi, J. Excellent photocatalytic degradation of methylene blue, rhodamine $\mathrm{b}$ and methyl orange dyes by Ag-ZnO nanocomposite under nat-ural sunlight irradiation. Optik 2021, 231, 166518.

27. Beura, R.; Pachaiappan, R.; Paramasivam, T. Photocatalytic degradation studies of organic dyes over novel Ag-loaded ZnOgraphene hybrid nanocomposites. J. Phys. Chem. Solids 2021, 148, 109689. [CrossRef]

28. Podasca, V.-E.; Damaceanu, M.-D. ZnO-Ag based polymer composites as photocatalysts for highly efficient visible-light degradation of Methyl Orange. J. Photochem. Photobiol. A Chem. 2021, 406, 113003. [CrossRef]

29. Phuruangrat, A.; Siri, S.; Wadbua, P.; Thongtem, S.; Thongtem, T. Microwave-assisted synthesis, photocatalysis and antibacterial activity of Ag nanoparticles supported on ZnO flowers. J. Phys. Chem. Solids 2019, 126, 170-177. [CrossRef]

30. Babu, A.T.; Antony, R. Green synthesis of silver doped nano metal oxides of zinc \& copper for antibacterial properties, adsorption, catalytic hydrogenation \& photodegradation of aromatics. J. Environ. Chem. Eng. 2019, 7. [CrossRef]

31. Ata, S.; Shaheen, I.; Qurat-ul-Ayne Ghafoor, S.; Sultan, M.; Majid, F.; Bibi, I.; Iqbal, M. Graphene and silver decorated ZnO composite synthesis, characterization and photocatalytic activity evaluation. Diam. Rel. Mater. 2018, 90, 26-31. [CrossRef]

32. Pathak, T.K.; Kroon, R.E.; Swart, H.C. Photocatalytic and biological applications of Ag and Au doped ZnO nanomaterial synthe-sized by combustion. Vacuum 2018, 157, 508-513. [CrossRef]

33. Rashid, J.; Barakat, M.A.; Salah, N.; Habib, S.S. Ag/ZnO nanoparticles thin films as visible light photocatalysts. RSC Adv. 2014, 4, 56892-56899. [CrossRef]

34. Lv, J.; Yang, Z.; Wang, C.; Wang, S.; Ma, Y.; Zhou, G.; Jiang, J.; Zhu, Q.; Zhao, M.; Chen, X. Effect of vacuum annealing on solar light response and photocatalytic performance of Ag nanoparticle-modified ZnO thin films. Appl. Phys. A 2020, 126, 1-6. [CrossRef]

35. Munawar, K.; Mansoor, M.A.; Olmstead, M.M.; Zaharinie, T.; Mohd Zubir, M.N.; Haniffa, M.; Basirun, W.J.; Mazhar, M. Fabrication of Ag-ZnO composite thin films for plasmonic enhanced water splitting. Mater. Chem. Phys. 2020, 255, 123220. [CrossRef]

36. Ravichandran, K.; Uma, R.; Sriram, S.; Balamurgan, D. Fabrication of ZnO:Ag/GO composite thin films for enhanced photocatalytic activity. Ceram. Int. 2017, 43, 10041-10051. [CrossRef]

37. Gilliot, M.; Hadjadj, A.; Naciri, A.E. Dielectric function of very thin nano-granular ZnO layers with different states of growth. Appl. Opt. 2015, 54, 3043-3050. [CrossRef]

38. Gilliot, M.; Hadjadj, A.; Martin, J. Investigation of the correlation between dielectric function, thickness and morphology of nano-granular ZnO very thin films. Thin Solid Films 2015, 597, 65-69. [CrossRef]

39. Gilliot, M.; Hadjadj, A. Correlated effects of preparation parameters and thickness on morphology and optical properties of ZnO very thin films. J. Cryst. Growth 2015, 423, 38-44. [CrossRef]

40. Quintero, L.; Cardona, S. Technologies for the decolorization of dyes: Indigo and indigo carmine [Tecnologías para la decoloración de tintes índigo e índigo carmín]. DYNA 2010, 77, 371-386.

41. Gilliot, M.; Eypert, C.; Hadjadj, A. Dielectric function of sol-gel prepared nano-granular zinc oxide by spectroscopic ellipsometry. J. Appl. Phys. 2013, 114, 183513. [CrossRef] 
42. Levi, S.; Mancier, V.; Rousse, C.; Garcia, O.L.; Mejia, J.; Guzman, M.; Lucas, S.; Fricoteaux, P. Synthesis of spherical copper-platinum nanoparticles by sonoelectrochemistry followed by conversion reaction. Electrochim. Acta 2015, 176, 567-574. [CrossRef]

43. Boussatha, N.; Gilliot, M.; Ghoualem, H.; Martin, J. Formation of nanogranular ZnO ultrathin films and estimation of their per-formance for photocatalytic degradation of amoxicillin antibiotic. Mater. Res. Bull. 2018, 99, 485-490. [CrossRef]

44. McMurdie, H.; Morris, M.; Evans, E.; Paretzkin, B.; Wong-NG, W.; Hubbard, C. Methods of producing standard X-Ray diffraction powder patterns. Powder Diffraction 1986, 1, 40-43. [CrossRef]

45. Lyadov, N.M.; Gumarov, A.; Kashapov, R.N.; Noskov, A.I.; Valeev, V.F.; Nuzhdin, V.I.; Bazarov, V.V.; Khaibullin, R.I.; Faizrakhmanov, I.A. Structure and optical properties of ZnO with silver nanoparticles. Semicond 2016, 50, 43-49. [CrossRef]

46. Lelong, A.; Sakli, A.; Zeinert, A.; Lejeune, M. Carbon copper thin films for discoloration of indigo carmine. Vacuum 2018, 148, 136-139. [CrossRef]

47. Gordon, P.F.; Gregory, P. Colour and Constitution of Indigoid Dyes in "Organic Chemistry in Colour"; Springer: New York, NY, USA, 1983; p. 211.

48. Lu, W.; Gao, S.; Wang, J. One-pot synthesis of Ag/ZnO self-assembled 3D hollow microspheres with enhanced photocatalytic per-formance. J. Phys. Chem. C 2008, 112, 16792-16800. [CrossRef]

49. Arabatzis, I.M.; Stergiopoulos, T.; Andreeva, D.; Kitova, S.; Neophytides, S.G.; Falaras, P. Characterization and photocatalytic activity of $\mathrm{Au} / \mathrm{TiO}_{2}$ thin films for azo-dye degradation. J. Catal. 2003, 220, 127-135. [CrossRef]

50. You, X.; Chen, F.; Zhang, J.; Anpo, M. A novel deposition precipitation method for preparation of Ag-loaded titanium dioxide. Catal. Lett. 2005, 102, 247-250. [CrossRef]

51. Shinde, S.G.; Patil, M.P.; Kim, G.-D.; Shrivastava, V.S. Multi-doped ZnO Photocatalyst for Solar Induced Degradation of Indigo Carmine Dye and as an Antimicrobial Agent. J. Inorg. Organomet. Polym. Mater. 2019, 30, 1141-1152. [CrossRef]

52. Kubacka, A.; Fernández-García, M.; Colón, G. Advanced nanoarchitectures for solar photocatalytic applications. Chem. Rev. 2011, 112, 1555-1614. [CrossRef]

53. Vautier, M.; Guillard, C.; Herrmann, J.-M. Photocatalytic degradation of dyes in water: Case study of indigo and of indigo carmine. J. Catal. 2001, 201, 46-59. [CrossRef]

54. Nagaraj, B.; Devi, L.G. Silver metalized mixed phase manganese-doped titania: Variation of electric field and band bending within the space charge region with respect to the silver content. J. Mol. Catal. A Chem. 2014, 390, 142-151. [CrossRef]

55. Christopher, P.; Ingram, D.B.; Linic, S. Enhancing photochemical activity of semiconductor nanoparticles with optically active Ag nanostructures: Photochemistry mediated by Ag surface plasmons. J. Phys. Chem. C 2010, 114, 9173-9177. [CrossRef]

56. Zhang, Y.; Wang, C.; Wang, J.; Chen, L.; Li, J.; Liu, Y.; Zhao, X.; Wang, Y.; Yang, J. Nanocap array of Au:Ag composite for surface-enhanced Raman scattering. Spectrochim. Acta Part. A Mol. Biomol. Spectrosc. 2016, 152, 461-467. [CrossRef] [PubMed]

57. Jain, P.K.; Huang, W.; El-Sayed, M.A. On the universal scaling behavior of the distance decay of plasmon coupling in metal nano-particle pairs: A plasmon ruler equation. Nano Lett. 2007, 7, 2080-2088. [CrossRef]

58. Tabor, C.; Murali, R.; Mahmoud, M.; El-Sayed, M.A. On the use of plasmonic nanoparticle pairs as a plasmon ruler: The dependence of the near-field dipole plasmon coupling on nanoparticle size and shape. J. Phys. Chem. A 2009, 113, 1946-1953. [CrossRef]

59. Wei, J.; Jiang, N.; Xu, J.; Bai, X.; Liu, J. Strong coupling between ZnO excitons and localized surface plasmons of silver nanoparticles studied by STEM-EELS. Nano Lett. 2015, 15, 5926-5931. [CrossRef]

60. Labhane, P.; Sonawane, S.; Patil, S.; Huse, V. Influence of Mg doping on ZnO nanoparticles decorated on graphene oxide (GO) crumpled paper like sheet and its high photo catalytic performance under sunlight. J. Phys. Chem. Solids 2018, 114, 71-82. [CrossRef]

61. Prado, A.G.; Bolzon, L.B.; Pedroso, C.P.; Moura, A.O.; Costa, L.L. $\mathrm{Nb}_{2} \mathrm{O}_{5}$ as efficient and recyclable photocatalyst for indigo carmine degradation. Appl. Catal. B Environ. 2008, 82, 219-224. [CrossRef]

62. Güy, N.; Özacar, M. Visible light-induced degradation of indigo carmine over $\mathrm{ZnFe}_{2} \mathrm{O}_{4} /$ Tannin/ZnO: Role of tannin as a modifier and its degradation mechanism. Int. J. Hydrogen Energy 2018, 43, 8779-8793. [CrossRef] 